\title{
TECHNIQUES FOR FULL-THICKNESS KERATOPLASTY IN RABBITS USING FRESH AND FROZEN CORNEAL TISSUE*
}

\author{
BY \\ F. O. MUELLER $†$ \\ National Institute for Medical Research, Mill Hill, London, and the Corneo-Plastic Unit and Regional Eye \\ Bank, Queen Victoria Hospital, East Grinstead, Sussex
}

THE early history of corneal grafting has been described in detail (Rycroft, 1955). After the second world war the use of antibiotics increased the safety of the procedure and the frequency with which it was performed. As a result, the demand for human donor corneal tissue increased greatly. The establishment of human eye banks became necessary and the passing of the Corneal Grafting Bill in Great Britain (Rycroft, 1953) made them possible.

Satisfactory full-thickness grafts were obtained from human eyes kept up to 4 days at $+4^{\circ} \mathrm{C}$., but only occasionally from eyes stored for 2 to 4 weeks at that temperature (Rycroft, 1955, 1962). Other methods of preserving the cornea, including storage at low temperatures, freeze-drying, or treatment with chemicals, proved to be fully satisfactory for lamellar grafts but not for full-thickness grafts. For example, Eastcott, Cross, Leigh, and North (1954) transplanted discs of corneal tissue which had been stored at $-79^{\circ} \mathrm{C}$. in the presence of 15 per cent. glycerol; the results of the lamellar grafts were excellent but most of the full-thickness grafts were only partially clear. Similar experiences were reported by Stocker, Matton, Eiring, Georgiade, and Georgiade (1960), King, (1960), Rycroft (1962), and other teams using various techniques for long-term storage.

There is evidence that success of full-thickness corneal grafts depends upon the presence of a living endothelium; procedures which killed the endothelial cells might have caused the failure of banked cornea (Smith, 1962). We therefore decided to preserve the viability of rabbit corneal endothelium at low temperatures. In vitro studies showed that the cornea is impermeable to glycerol and to the more recently introduced protective agent dimethyl sulphoxide. A technique was therefore developed for injecting solutions containing these substances into the anterior chamber. The results of tissue cultures showed that, in the presence of 7.5 to 15 per cent. dimethyl sulphoxide (DMSO), the endothelium survived cooling to and thawing from $-79^{\circ} \mathrm{C}$. (Smith, Ashwood-Smith, and Young, 1963). Preliminary trials of full-thickness keratoplasty, which were encouraging, have already been described (Mueller and Smith, 1963).

The purpose of this paper is to report the full results of the different groups of experiments on grafting fresh and frozen corneal tissue in rabbits.

- Received for publication October 10, 1963.

† Present address: Westminster Hospital, London, S.W.1. 


\section{Animals and Methods}

Young adult Dutch rabbits 1.5 to $2 \mathrm{~kg}$. in weight were used. In some animals the irises showed partial albinism (see Plate I, opposite, and Plate II, overleaf).

A full-thickness corneal graft was performed on only one eye of each rabbit. Donor and recipient always differed in sex. Donors were killed by air embolism. Both eyes were enucleated and either frozen or used as controls within 2 to 5 hours of death. Blood was collected from large lop-eared and albino rabbits. The serum was sterilized by Seitz filtration; sterile horse serum was obtained from Oxo Limited.

The eyes were prepared for freezing by injecting the anterior chambers with a medium containing either DMSO, or glycerol in serum, and then suspended in a medium containing either DMSO or glycerol in a mixture of equal parts of serum and Gey's solution (see Mueller and Smith, 1963). Some eyes which had been injected with and suspended in these media were used as donor material for control fullthickness corneal grafts of unfrozen tissue.

The needle for irrigating the anterior chamber has been described recently (Smith and others, 1963). This needle, with its stylet in place, was introduced into the anterior chamber by piercing the sclera behind the iris diaphragm. The pressure applied to facilitate puncture was then reduced. The eye was held with the cornea facing upwards so that the lens fell back while the needle passed in front of it, behind the iris, and across the pupil. At the time of counter-puncture of the sclera the intra-ocular pressure was again increased. $3 \mathrm{ml}$. of the medium for preserving the endothelium were then slowly injected so that the aqueous humour was replaced without raising the intra-ocular pressure (see Plate I, Fig. 1). The needle was then rapidly withdrawn. The eye was suspended on an aluminium frame and sealed inside a glass tube 1 inch in diameter containing the medium for preserving the epithelium. The whole eye was then cooled slowly to $-79^{\circ} \mathrm{C}$. using the apparatus described by Polge and Lovelock (1952). Eyes so treated were banked for periods varying from one hour to 116 days.

Medication.-1 $\mathrm{ml}$. 1 per cent. atropine sulphate was injected subcutaneously $30 \mathrm{~min}$. before the induction of general anaesthesia. In preliminary experiments various pre-operative medications were tested for dilatation of the pupil before and during operation. Aqueous solutions of either 1 per cent. atropine sulphate, 1 per cent. ephedrine, 10 per cent. phenyl-ephrene, 0.5 per cent. cyclopentholate hydrochloride, or else an oily suspension of 1 per cent. ephedrine were applied to the eyes at 10-min. intervals, beginning 1 hour before operation. In some of the early experiments one of these drugs, or 1:1,000 adrenaline, was dropped continuously on to the eye during keratoplasty.

FIg. 1.-Preparation of a rabbit eye for freezing. The irrigation needle is in position across the anterior chamber behind the iris.

Fig. 2.-Graft from an eye kept 51 days at $-79^{\circ} \mathrm{C}$ at the end of operation.

Fig. 3.-Graft from an eye kept 42 days at $-79^{\circ} \mathrm{C}$., 12 days after keratoplasty. Note staphyloma at limbus.

FIG. 4. - Graft from an eye kept 11 days at $-79^{\circ} \mathrm{C}$., 12 weeks after keratoplasty. Note suture marks and scar at host-graft junction.

Fig. 5.-Graft from an eye kept 2 days at $-79^{\circ} \mathrm{C}$., 8 weeks after operation. Note superficial opacity.

Fig. 6.-The same eye as in Fig. 5, 42 weeks after keratoplasty. The opacity has been removed by superficial keratectomy. 
1

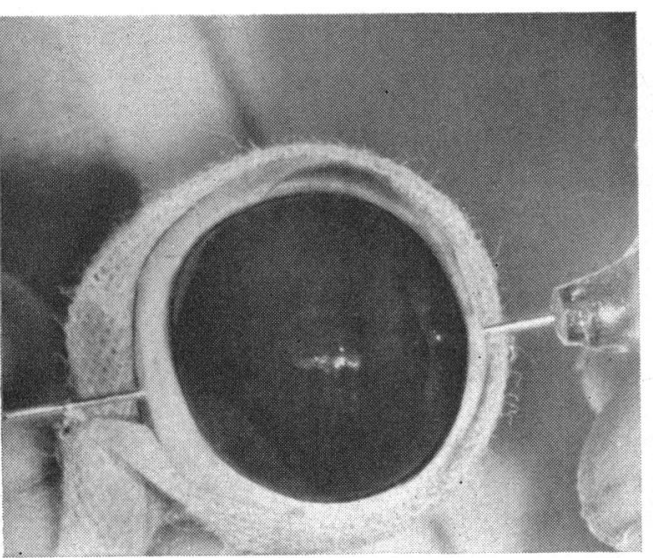

3

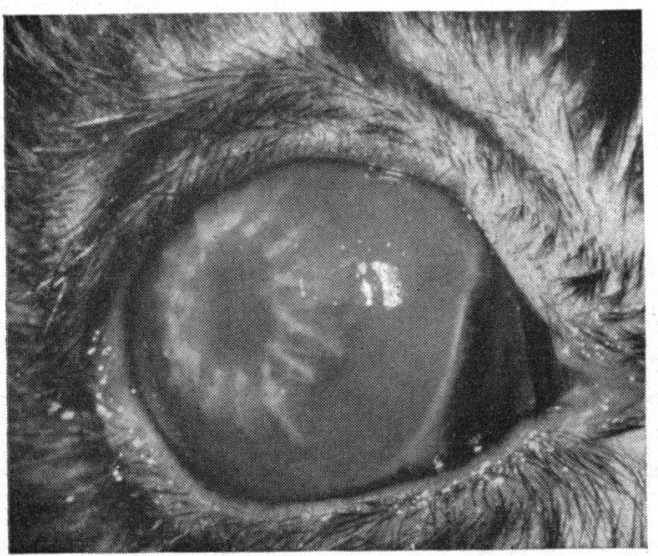

5

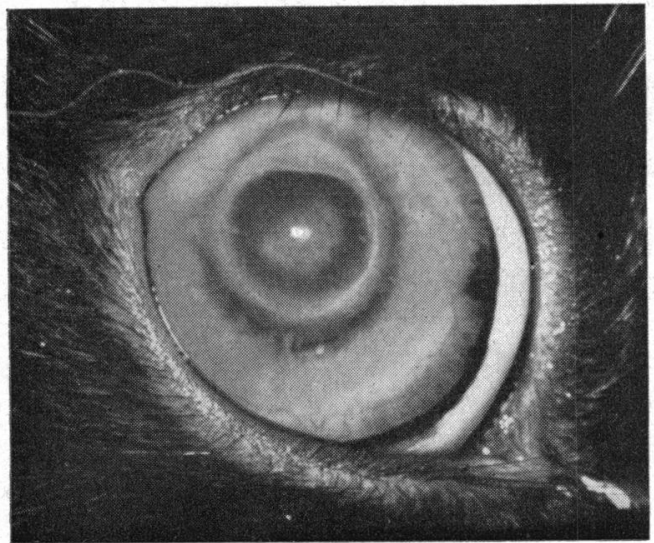

Plate I (Figs 1-6).

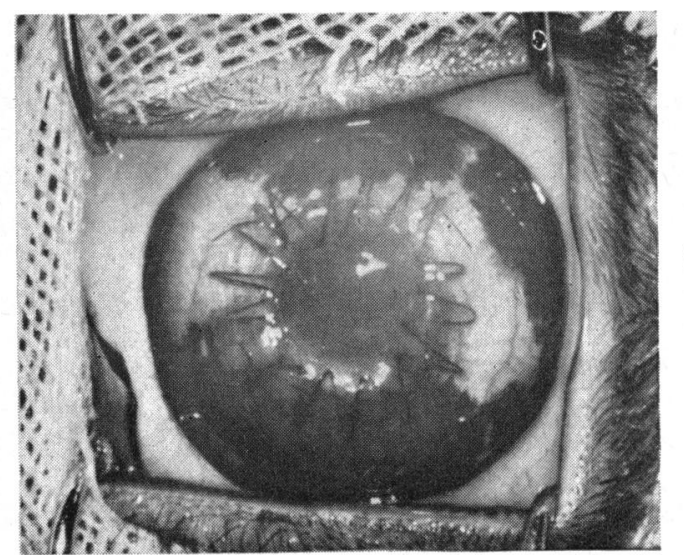


$0.5 \mathrm{ml}$. mydricaine (Moorfields No. 2) was injected subconjunctivally either before or at the end of the operation. Finally, at the end of the operation, one of the mydriatics was applied into the fornices.

In preliminary experiments the disodium salt of ethylene-diamine-tetra-acetic acid (EDTA) $(0 \cdot 5,1$, or 2 per cent.) was applied continuously to the cornea during operation to prevent clotting of the aqueous humour. In other preliminary experiments 0.5 per cent. heparin or dilute fibrinolysin (100 units $/ \mathrm{ml}$.) was dropped into the anterior chamber. These techniques were unsatisfactory and were abandoned in favour of injecting 500 to 800 units heparin intravenously.

Anaesthesia.-Open ether was used routinely for keratoplasty. There were only three deaths under the anaesthetic in the entire series of experiments.

Preparation and Handling of the Graft.- At the time of induction of anaesthesia the eye which had been banked at $-79^{\circ} \mathrm{C}$. was thawed rapidly (see Mueller and Smith, 1963). As soon as all ice attached to the cornea had disappeared and while the lens was still frozen, the outer surface of the cornea was gently washed, preferably with 5 per cent. glycerol in serum followed by pure serum. In early experiments the corneal epithelium was removed. Later, it was left intact. The centre of the cornea was then trephined with a Francheschetti trephine. In the standard technique in the majority of experiments the 6.0 and $6.1 \mathrm{~mm}$. trephines were used. Resection of the graft was completed using Rycroft's corneal scissors. The disc was lifted by a pre-placed suture from the donor eye and placed with the epithelium downwards in a Petri dish lined with moist filter paper. Not more than $5 \mathrm{~min}$. elapsed before the graft was transferred to the prepared eye of the recipient.

Preparation of the Recipient Eye.-The eyes were kept open using a Barraquer's wire speculum, and immobilized by holding the superior rectus muscle with toothed forceps while the cornea was trephined.

In early experiments a deep lamella $7 \mathrm{~mm}$. in diameter was removed from the host cornea; the centre of the exposed stroma was then trephined with a 5-mm. trephine, leaving a ledge to support the margin of the graft. In the majority of experiments a single cut with a $6.1 \mathrm{~mm}$. trephine was made through all three layers and resection of the disc was completed with scissors. In some experiments the iris sphincter was cut, but not if heparin had been administered intravenously.

Suturing and Post-operative Treatment.-The donor disc was transferred by its pre-placed suture into the prepared bed in the cornea of the host and fixed by multiple direct sutures or by a continuous suture.

In preliminary experiments, either air, acetylcholine, or adrenaline was injected through the host graft junction to restore the depth of the anterior chamber. An

Fig. 7.-Unfrozen control graft, 26 weeks after operation.

FIG. 8. -Graft from eye kept 19 days at $-79^{\circ} \mathrm{C}$., 28 weeks after operation.

Fig. 9.-Graft from eye kept 106 days at $-79^{\circ} \mathrm{C}$., 12 weeks after operation.

FIG. 10. Graft from eye kept 114 days at $-79^{\circ} \mathrm{C}$., 12 weeks after operation. Note fine opacification at margin of graft.

Fig. 11.-Graft from eye kept 8 days at $-79^{\circ} \mathrm{C}$, 8 weeks after operation.

Fig. 12.-Graft from eye kept 38 days at $-79^{\circ} \mathrm{C}$., 10 weeks after operation. 

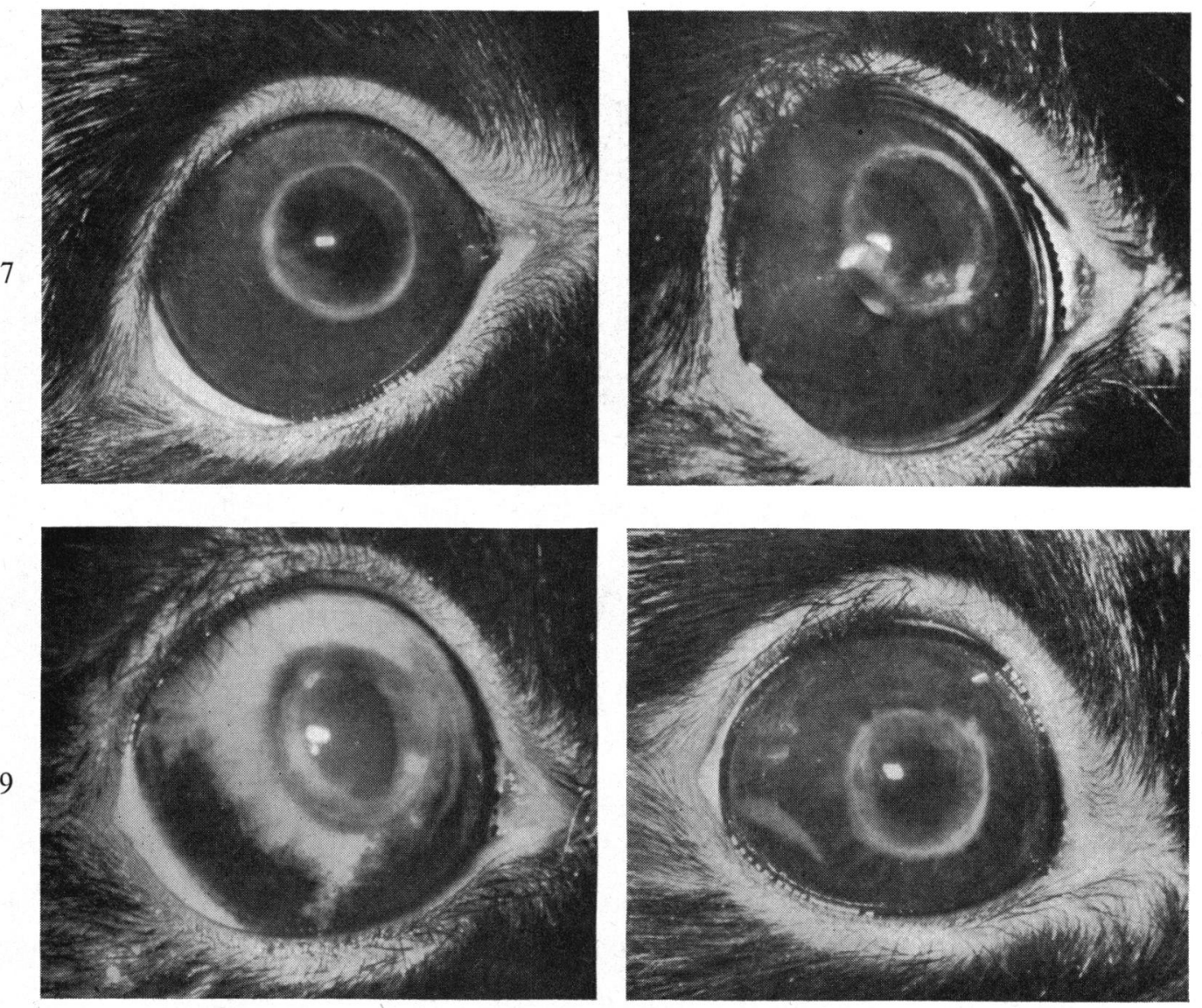

10
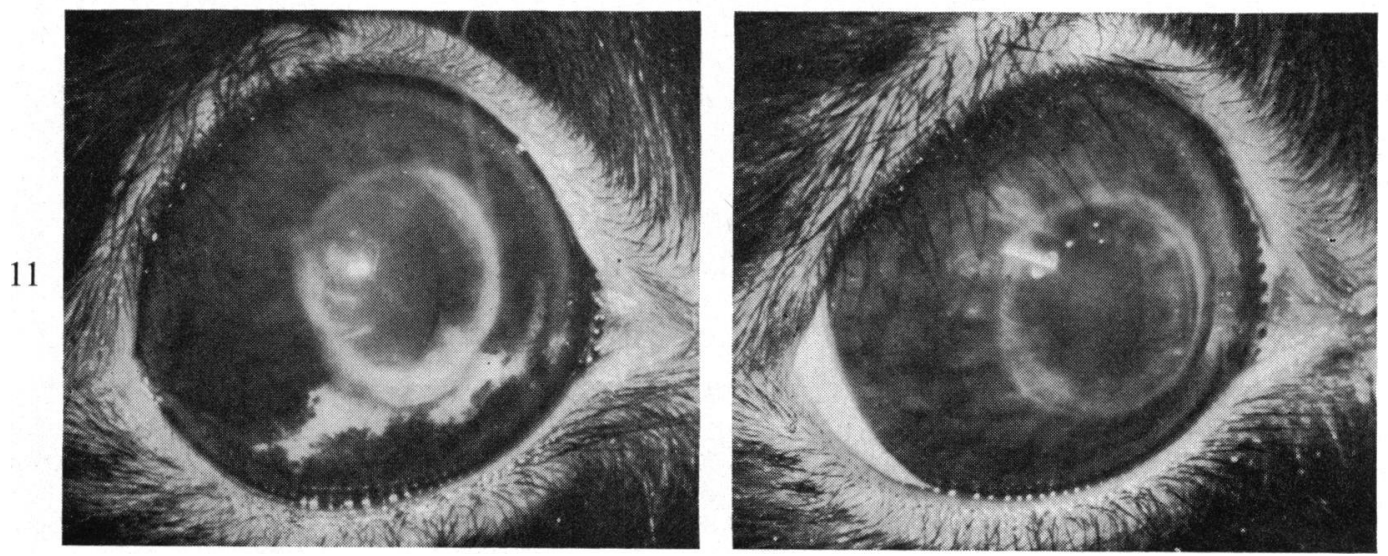

Plate II (Figs 7-12).

Full-thickness homografts of rabbit cornea. The media contained horse serum (Figs 7 to 10) and rabbit serum (Figs 11, 12). 
antibiotic and a mydriatic were either instilled under the lids or injected subconjunctivally. Occasionally the lids were closed with two sutures. The sutures were removed 10 to 21 days after keratoplasty, and a subconjunctival injection of $0.5 \mathrm{ml}$. hydrocortisone acetate was given and an antibiotic was instilled. The only subsequent treatment was with oculentum hydrocortisone if vascularization persisted.

Final Technique. -1 per cent. ephedrine in oil was instilled into the eye $40 \mathrm{~min}$. before operation and at 10-min. intervals thereafter. A subcutaneous injection of $1 \mathrm{ml} .1$ per cent. atropine sulphate was given $30 \mathrm{~min}$. before induction of anaesthesia with ether. As soon as the animal reached the third stage of anaesthesia, $0.5 \mathrm{ml}$. mydricaine was injected subconjunctivally and 500 units heparin were given intravenously. The eye was then prepared for operation.

Meanwhile the donor eye had been thawed and the graft cut with a $6.1 \mathrm{~mm}$. trephine and placed in a moist chamber. The recipient eye was washed with serum; the speculum was inserted to separate the lids and the eye was fixed and trephined with a $6 \cdot 0-\mathrm{mm}$. trephine. At this stage the deepest possible anaesthesia was essential. After the disc of host cornea had been separated with scissors and discarded, the donor disc was lifted into position using the pre-placed suture. The graft was anchored with four meridional sutures using a 4-mm. Barraquer needle and virgin silk. Finally, the host-graft junction was sealed with a continuous suture (see Plate I, Fig. 2). Oculentum chloromycetin and two drops 1 per cent. ephedrine in oil were instilled at the end of the operation; the wire speculum was removed and the lids were gently closed.

When this standard technique was followed the entire operation, including induction of anaesthesia, lasted, on average, $35 \mathrm{~min}$.

\section{Recording Results}

Results were assessed by the method described previously (Mueller and Smith, 1963) and recorded as follows:

$$
\begin{aligned}
0 & =\text { failure } \\
+ & =\text { partially clear; iris faintly visible } \\
++ & =\text { clear so that details in the iris were visible } \\
+++ & =\text { no opacity in any part of the graft }
\end{aligned}
$$

Results recorded as +++ and ++ indicate successful corneal grafts. Many of the operated eyes were photographed to complete the records.

\section{Operative and Post-operative Complications}

The lens was damaged while trephining the host cornea in two out of the 633 operations performed. Haemorrhage occurred after iridectomy, and subsequently anterior synechiae formed. When intravenous heparin was used there was mild intra-ocular haemorrhage in two rabbits but anterior synechiae did not form.

Corneal infections were rare but caused keratitis with hypopyon in two animals. Sloughing of epithelium and superficial layers of stroma occurred in a small number of grafts with severe guttering at the host-graft junction. Only a few of these grafts regained full clarity 3 to 4 months after operation. 
A rise in intra-ocular pressure developed at the end of the first post-operative week in many of the early experiments. It was due to clotting of the aqueous humour and formation of anterior synechiae at the host-graft junction. The outcome was either a localized staphyloma near the limbus or rupture of the host-graft junction (Plate I, Fig. 3). After intravenous injection of heparin this complication was rare, although isolated anterior synechiae occasionally caused oedema or localized opacities in the graft (Plate II, Fig. 10).

Superficial vascularization extending $2 \mathrm{~mm}$. into the transplant occurred in most instances, but usually disappeared soon after the removal of sutures, or after the application of hydrocortisone. In the majority of rabbits the stitch marks and the scar at the host-graft junction persisted (see Plate I, Fig. 4; Plate II).

Superficial opacities appeared about 2 months after operation in ten frozen grafts and in five unfrozen grafts. Some of these opacities increased in size and density; some disappeared slowly during the next 3 to 4 months. In three animals the opacity of the graft was treated by scraping off the overlying epithelium and then irrigating the area with 1 per cent. EDTA. In two animals it was removed by a superficial keratectomy (Plate I, Figs 5 and 6).

\section{Premedication with Miotics and Mydriatics}

The only mydriatics which dilated the pupil satisfactorily were 1 per cent. ephedrine in oil together with a subconjunctival injection of mydricaine (Moorfields No. 2). In a series of 100 preliminary experiments various other mydriatics were tested, but the results were unsatisfactory. It was concluded that aqueous solutions of ephedrine or any other drug caused oedema of the stroma and sloughing of the epithelium. Cocaine and its derivatives proved to be toxic to tissue cultures of corneal cells (Smith, personal communication).

In thirty experiments 1 per cent. ephedrine in oil was instilled and a subconjunctival injection of mydricaine was given to the anaesthetized rabbit. The pupils remained either partially or fully dilated until the end of operation. This method was therefore adopted as a routine for the next 230 operations.

\section{Clotting of Aqueous Humour and its Prevention}

Use of EDTA.-In the first group of experiments, EDTA $(0 \cdot 5,1$, or 2 per cent. in physiological saline) was dropped on the eye continuously throughout the operation. In 48 of these experiments the iris sphincter was cut before the donor disc was placed into its bed; air was injected into the anterior chamber at the end of operation. During the operation there was haemorrhage and clotting, and anterior synechiae formed with the sequelae already described. The majority of rabbits had to be killed and 3 months later only three remained with clear grafts. Sphincterotomy was therefore abandoned.

In the next twenty experiments in which EDTA was instilled, clotting occurred although there was no haemorrhage. Air was injected into the anterior chamber. Nevertheless, anterior synechiae formed with the usual consequences, so that only two rabbits with clear grafts remained 3 months after operation. The injection of air was therefore discontinued. 
In the next six experiments, mydricaine was given at the beginning of the operation and EDTA was instilled during operation. The aqueous humour clotted, anterior synechiae formed, and no clear grafts were obtained.

Use of Fibrinolysin. $-2 \mathrm{ml}$. containing 200 units fibrinolysin were continuously instilled into six eyes during operation. Clotting was prevented, but in two experiments the suspensory ligaments were dissolved and the lens extruded and lost. In all six experiments the edges of the graft and of the trephined hole in the host cornea were digested and suturing across the wide gap became impossible.

Local Use of Heparin.-In 43 experiments, 0.5 per cent. heparin was instilled into the eye throughout the operation. Only four of the 43 grafts were clear 3 months after operation. Local application of heparin caused less oedema of epithelium and stroma but was even less effective as an anticoagulant than EDTA. The failures were due to numerous anterior synechiae and secondary glaucoma resulting from inadequate control of clotting. It was therefore decided to use intravenous heparin in spite of the risk of intra-ocular haemorrhage.

Use of Intravenous Heparin.-In twelve experiments, 500 to 800 units heparin were given intravenously to the anaesthetized rabbit and $0.5 \mathrm{ml}$. mydricaine was injected subconjunctivally. There was no clotting of aqueous humour during operation. All twelve grafts were successful and were clear 1 month after operation and thereafter. In subsequent experiments heparin was given intravenously as a routine.

Size of Trephines.-In 39 experiments, a 7-mm. full-thickness disc of fresh unfrozen corneal tissue was sutured into the prepared bed in the host cornea. This had an outer diameter of $7 \mathrm{~mm}$. and a central aperture $5 \mathrm{~mm}$. in diameter. This procedure prolonged the operation to $45 \mathrm{~min}$., and a perfect wound seal was not obtained. Only seven of the 39 grafts became clear.

In forty experiments, donor and host eyes were trephined with a $6 \cdot 0-\mathrm{mm}$. trephine. Subsequently the trephine hole in the host cornea increased in diameter. At the end of operation the sutures were under tension and there appeared to be folds in the deeper layers of the graft. Only sixteen of the forty grafts became clear.

In 56 experiments, a $6 \cdot 1-\mathrm{mm}$. full-thickness disc of fresh unfrozen corneal tissue was placed into a 6-mm. trephine hole in the host cornea. The graft fitted well and did not become folded. This technique was therefore adopted as a routine.

Technique of Suturing. - In forty experiments eight interrupted direct sutures were used, but wound closure was inadequate. When fourteen or sixteen sutures were inserted there was pronounced vascularization of the host cornea and oedema of the graft.

In other experiments unfrozen donor discs were anchored by four direct meridional sutures and the host-graft junctions closed by continuous sutures. Vascularization of the host cornea was delayed and was milder than in the presence of multiple interrupted sutures; oedema of the graft was reduced. Use of this technique of wound closure after intravenous heparin gave twenty out of twenty grafts which were 
clear 1 month later and thereafter. Continuous sutures were therefore adopted in the standard technique.

Use of Hydrocortisone. - Repeated local administration of hydrocortisone during the first two post-operative weeks retarded wound healing, sutures tended to cut out, and some grafts actually dropped out. The use of hydrocortisone was therefore avoided until after the sutures had been removed.

\section{Unfrozen Control Grafts}

From rabbit eyes treated with dimethyl sulphoxide (DMSO) and glycerol diluted in horse serum.- In preliminary experiments the anterior chambers of donor eyes were irrigated with decomplemented horse serum containing 7.5 or 15 per cent. DMSO, and the eyes were suspended in solutions containing either 7.5 per cent. DMSO or 10 per cent. glycerol. They were kept for 1 to $4 \mathrm{hrs}$ at $+2^{\circ} \mathrm{C}$. before full-thickness grafts for keratoplasty were cut, this being performed by the standard technique.

When the donor eyes had been injected with and suspended in 7.5 per cent. DMSO, only six of the ten grafts were successful. In the grafts injected with 15 per cent. DMSO and suspended in 10 per cent. glycerol, five out of nine clear grafts were obtained. By contrast, the series in which the donor eyes were injected with 7.5 per cent. DMSO and suspended in 10 per cent. glycerol, 32 out of 36 grafts were successful, and were clear from the 3rd week until the 8th month after operation. Four of these rabbits had to be killed because of complications.

From eyes injected with $7 \cdot 5$ per cent. DMSO and suspended in 10 per cent. glycerol in rabbit serum.--Seven eyes were used in control experiments to test media containing 7.5 per cent. DMSO and 10 per cent. glycerol in fresh rabbit serum. At the end of operation six out of the seven grafts were clear; the other graft became grossly oedematous during operation. Subsequently, four grafts showed slight vascularization of the host cornea at the end of the 2 nd week, but the vessels did not reach the host-graft junction and regressed immediately after removal of the sutures. In two of the seven eyes the host-graft junction separated during removal of sutures. One graft was lost because its superficial layers sloughed and a scar formed. Only four of the grafts were clear at the 8th and 12th weeks (see Table I, overleaf).

From eyes treated with DMSO and glycerol diluted with heated rabbit serum.-Four grafts were cut from eyes which had been injected with $7 \cdot 5$ per cent. DMSO and suspended in 10 per cent. glycerol. The media contained rabbit serum which had been heated for $60 \mathrm{~min}$. at $+55^{\circ} \mathrm{C}$. Three grafts were clear and one graft slightly oedematous at the end of operation. The superficial layers of one graft sloughed at the beginning of the 2 nd week. There was only slight vascularization. Subsequently scar tissue formed. The other three grafts and the host corneae remained free from vascularization and were clear at the 12th week (see Table I). The impression from this small group was that decomplementing the rabbit serum had slightly improved its qualities as a vehicle for the DMSO and the glycerol. 
TABLE I

UNFROZEN CONTROL GRAFTS FROM EYES INJECTED WITH 7.5 PER CENT. D.M.S.O., SUSPENDED IN 10 PER CENT. GLYCEROL, AND DILUTED IN RABBIT SERUM

\begin{tabular}{|c|c|c|c|c|c|c|}
\hline \multirow{2}{*}{ Media } & \multirow{2}{*}{$\begin{array}{l}\text { Number } \\
\text { of } \\
\text { Rabbits }\end{array}$} & \multicolumn{4}{|c|}{ Clear Grafts } & \multirow{2}{*}{$\begin{array}{l}\text { Proportion } \\
\text { of } \\
\text { Satisfactory } \\
\text { Clear Grafts }\end{array}$} \\
\hline & & $\begin{array}{c}\text { At } \\
\text { Operation }\end{array}$ & 3 wks later & 8 wks later & 12 wks later & \\
\hline Fresh rabbit serum & 7 & 6 & 5 & 4 & 4 & $4 / 7$ \\
\hline Heated rabbit serum & 4 & 3 & 4 & 3 & 3 & $3 / 4$ \\
\hline $\begin{array}{c}\text { Concentration reduced } \\
\text { before operation }\end{array}$ & 9 & 9 & 6 & 6 & 6 & $6 / 9$ \\
\hline
\end{tabular}

Unfrozen Grafts from Eyes washed with Reduced Concentrations of DMSO and Glycerol

Sudden reduction in the concentration of DMSO in the anterior chambers and of glycerol in contact with the epithelium might have had harmful osmotic effects on the living cells in these layers and on the fibres in the stroma of the cornea. In an experiment designed to investigate this idea, the anterior chambers of nine eyes were irrigated with 7.5 per cent. DMSO and suspended in 10 per cent. glycerol diluted in rabbit serum. One hour later and shortly before operation, the concentration of glycerol in contact with the epithelium was reduced from 10 to $7 \cdot 5$ per cent. and then to 5 per cent. by dilution with serum, and 5 minutes later the epithelium was washed with pure serum. Next, the anterior chambers were slowly irrigated with $3 \mathrm{ml} .2 .5$ per cent. DMSO. Full-thickness grafts were then cut.

At the time of operation all the grafts were clear. Subsequently there was scarcely any vascularization of the host cornea. In the 3rd post-operative week three of the grafts developed ectasia and by the end of the 6th week they had been converted into scar tissue. The other six grafts were clear at the 3rd, 8th, and 12th weeks after keratoplasty.

The results of this experiment were slightly better than those of previous experiments (see Table I), suggesting that gradual reduction of the concentrations of glycerol and DMSO might have some advantage.

\section{Frozen Grafts}

From eyes treated with DMSO and glycerol and cooled to and kept at $-79^{\circ} \mathrm{C}$. for 1 to 2 hours. In preliminary experiments eleven rabbit eyes were injected with and suspended in 7.5 per cent. DMSO in horse serum. They were cooled to and kept at $-79^{\circ} \mathrm{C}$. for 1 to 2 hours. After thawing, full-thickness grafts were cut and keratoplasty was performed by the standard technique. Only one of the eleven grafts became clear at the 3rd week and remained clear thereafter.

In another group of experiments twelve eyes were injected with 15 per cent. DMSO and suspended in 10 per cent. glycerol in horse serum before cooling slowly to $-79^{\circ} \mathrm{C}$. After 1 to 2 hours they were thawed, grafts were cut, and full-thickness keratoplasty was performed. In this group two grafts were clear at the $3 \mathrm{rd}$ week and four at the 12 th week after operation. The other rabbits had to be killed because of surgical 
complications. These results were encouraging and suggested that the use of glycerol was to be preferred to DMSO for protecting the corneal epithelium.

In a third experiment twelve eyes were injected with 7.5 per cent. DMSO in horse serum and treated with 10 per cent. glycerol externally before cooling to $-79^{\circ} \mathrm{C}$. After 1 to 2 hours they were thawed and full-thickness discs were cut and grafted. In spite of the fact that the donor eyes had been frozen, the tissue was almost indistinguishable from fresh, unfrozen material. During the next fortnight the grafts became slightly clouded and the host-graft junction was vascularized. After the sutures had been removed the blood vessels regressed and improvement continued steadily so that by the 12th week six of the frozen grafts were perfect, a seventh was satisfactory, and another was partially clear. There were only two failures. Eight of the ten remaining grafts were indistinguishable from unfrozen control grafts 16 weeks after operation. A large number of eyes was therefore prepared in this way and banked at $-79^{\circ} 3 \mathrm{C}$. for subsequent full-thickness corneal grafting.

From eyes banked at $-79^{\circ} \mathrm{C}$. for 1 to 114 days.-The anterior chambers of 44 rabbit eyes were irrigated with 7.5 per cent. DMSO in horse serum. They were suspended in diluted horse serum containing 10 per cent. glycerol. The glass tubes were sealed, cooled slowly to and banked at $-79^{\circ} \mathrm{C}$. for varying periods. After rapid thawing, full-thickness corneal grafts were cut and keratoplasty was performed as soon as possible. At the time of operation the majority of transplants were clear from eyes kept for periods up to 51 days at $-79^{\circ} \mathrm{C}$. They could not be distinguished from grafts which had been frozen for 1 to 2 hours or from the unfrozen control grafts (see Table II). One week later, forty of the 44 grafts, including some of those kept for 9 to 16 weeks at $-79^{\circ} \mathrm{C}$., were transparent; at this stage the condition of the grafted eyes was similar to that of controls with unfrozen grafts. At the time of removal of sutures ten of the 44 previously frozen transplants were perfectly

TABLE II

FROZEN GRAFTS FROM EYES INJECTED WITH 7.5 PER CENT. D.M.S.O., SUSPENDED IN 10 PER CENT. GLYCEROL, AND DILUTED IN HORSE SERUM

\begin{tabular}{|c|c|c|c|c|c|}
\hline \multirow{2}{*}{$\begin{array}{c}\text { Number of } \\
\text { Rabbits }\end{array}$} & \multirow{2}{*}{$\begin{array}{l}\text { Days of } \\
\text { Storage }\end{array}$} & \multicolumn{3}{|c|}{ Clear grafts } & \multirow{2}{*}{$\begin{array}{l}\text { Proportion of } \\
\text { Satisfactory } \\
\text { Results }\end{array}$} \\
\hline & & At Operation & 8 wks later & 16 wks later & \\
\hline $\begin{array}{l}8 \\
5 \\
4 \\
1 \\
2 \\
2\end{array}$ & $\begin{array}{c}1-2 \\
7-14 \\
19-21 \\
23 \\
40 \\
51\end{array}$ & $\begin{array}{l}4 \\
5 \\
4 \\
1 \\
2 \\
2\end{array}$ & $\begin{array}{l}4 \\
3^{*} \\
4 \\
1 \\
2 \\
2\end{array}$ & $\begin{array}{l}6 \\
3 \\
4 \\
1 \\
2 \\
2\end{array}$ & $18 / 20$ \\
\hline $\begin{array}{l}2 \\
3 \\
2 \\
3 \\
3 \\
1 \\
1 \\
3\end{array}$ & $\begin{array}{r}61 \\
72 \\
79 \\
91 \\
106 \\
110 \\
112 \\
114\end{array}$ & $\begin{array}{l}0 \\
1 \\
1 \\
1 \\
1 \\
0 \\
0 \\
2\end{array}$ & $\begin{array}{l}1 \\
1 \\
0 \\
2 \\
1 \\
0 \\
0 \\
2\end{array}$ & $\begin{array}{l}2 \\
2 \\
1 \\
2 \\
1 \\
0 \\
0 \\
1\end{array}$ & $9 / 18$ \\
\hline
\end{tabular}

* Two rabbits died of intercurrent disease 2 weeks after operation. 
clear, twenty were slightly hazy, and six were moderately cloudy because of oedema. In every instance a few blood vessels had entered the grafts. There were only six completely opaque grafts and these were densely vascularized.

Soon after removal of sutures the corneal vessels regressed from the majority of grafts; 12 weeks after operation eighteen of the twenty grafts from eyes which had been banked at $-79^{\circ} \mathrm{C}$. for periods of one to 51 days were perfectly clear (Plate II, Fig. 8). After the same interval, nine of the eighteen grafts kept at $-79^{\circ} \mathrm{C}$. for 61 to 114 days were also clear (Plate II, Figs 9 and 10). The results are summarized in Table II. The failures may have been due to technical errors in preparing the eyes for freezing rather than to prolongation of the period of banking (see Discussion).

From eyes injected with DMSO and suspended in glycerol diluted with rabbit serum and then banked at $-79^{\circ} \mathrm{C}$.- - In the next series of experiments on frozen corneal tissue, rabbit serum was used instead of horse serum in the media containing the protective agents. Again the anterior chambers were irrigated with 7.5 per cent. DMSO and the eyes were suspended in 10 per cent. glycerol. The period of storage at $-79^{\circ} \mathrm{C}$. varied from 8 to 67 days, before thawing and full-thickness keratoplasty. At the end of operation, thirteen of the fifteen grafts were clear. The host-graft junctions did not become vascularized. At the end of the 12th post-operative week nine grafts were perfectly clear, as shown in Plate II, Fig. 11, two were slightly cloudy, and four were densely scarred. The results are summarized in Table III. The proportion of successful frozen grafts in this group was the same as in the control group of unfrozen grafts in which rabbit serum was used in the media. The fact that eyes banked for 64 and 67 days gave clear grafts, suggests that the duration of banking was not the cause of the failures, which are discussed on p. 390.

TABLE III

FROZEN GRAFTS FROM EYES INJECTED WITH $7 \cdot 5$ PER CENT. D.M.S.O. AND SUSPENDED IN 10 PER CENT. GLYCEROL DILUTED IN FRESH RABBIT SERUM

\begin{tabular}{c|c|c|c|c|c}
\hline \multirow{2}{*}{ Number of Rabbits } & Days of Storage & \multicolumn{4}{|c}{ Clear Grafts* } \\
\cline { 2 - 5 } & & At Operation & 3 wks later & 8 wks later & 12 wks later \\
\hline 5 & 8 & 5 & 3 & 4 & 4 \\
\hline 5 & 11 & 4 & 3 & 3 & 3 \\
\hline 2 & 55 & 2 & 0 & 0 & 0 \\
\hline 2 & 64 & 2 & 1 & 1 & 1 \\
\hline 1 & 67 & 0 & 0 & 1 & 1 \\
\hline
\end{tabular}

From frozen eyes treated with media containing protective substances in heated rabbit serum. $-7 \cdot 5$ per cent. DMSO in previously-heated rabbit serum was injected into the anterior chambers of 18 eyes. These eyes were suspended in 10 per cent. glycerol in the decomplemented serum. They were cooled to and banked at $-79^{\circ} \mathrm{C}$. for 10 to 57 days, and were then thawed, and grafts were cut for keratoplasty. At the end of operation ten donor discs were clear and the remaining eight were slightly 
clouded. Again, the lack of vascularization of host and graft cornea was conspicuous. At the end of the 12th post-operative week, eleven of the eighteen grafts were clear (Plate II, Fig. 12). The proportion of clear grafts was the same as in the group in which eyes were banked in media containing fresh, untreated rabbit serum, and lower than in the group in which decomplemented horse serum was used (see Tables I and IV).

TABLE IV

FROZEN GRAFTS FROM EYES INJECTED WITH 7.5 PER CENT. D.M.S.O. AND SUSPENDED IN 10 PER CENT. GLYCEROL IN SERUM HEATED $60 \mathrm{MIN}$. at $55^{\circ} \mathrm{C}$.

\begin{tabular}{c|c|c|c|c|c}
\hline \multirow{2}{*}{ Number of Rabbits } & Days of Storage & \multicolumn{4}{|c}{ Clear Grafts* } \\
\cline { 2 - 5 } & & At Operation & 3 wks later & 8 wks later & 12 wks later \\
\hline 8 & $10-11$ & 3 & 3 & 3 & 6 \\
\hline 4 & $34-38$ & 4 & 3 & 4 & 4 \\
\hline 2 & $41-43$ & 2 & 2 & 1 & 1 \\
\hline 3 & 45 & 1 & 0 & 0 & 0 \\
\hline 1 & 57 & 0 & 0 & 0 & 0 \\
\hline
\end{tabular}

From donor eyes banked at $-79^{\circ} \mathrm{C}$. and treated with reduced concentrations of the protective substances after thawing.-The anterior chambers of fourteen rabbit eyes were irrigated with 7.5 per cent. DMSO and the eyes were suspended in 10 per cent. glycerol. Fresh rabbit serum was the diluent. The specimens were banked at $-79^{\circ} \mathrm{C}$. for 11 to 71 days. During the process of thawing $10 \mathrm{ml} .5$ per cent. glycerol at $40^{\circ} \mathrm{C}$. were added to the medium surrounding the eyes; after completion of thawing the concentration of glycerol was again reduced by dilution of the medium with pure serum. Finally, the cornea was washed with pure rabbit serum. The anterior chamber was then slowly irrigated with $3 \mathrm{ml} .2 .5$ per cent. DMSO. Full-thickness grafts were cut and used immediately for keratoplasty.

Eleven of the fourteen grafts were clear at the end of operation. Eight grafts, one of which is shown in Plate I, Fig. 4, were satisfactory 8 weeks after operation and ten were clear at the 12 th week.

Vascularization of host and graft cornea was again conspicuous by its absence. Nevertheless, the proportion of satisfactory grafts was higher than in the previous groups in which rabbit serum was included in the media. The results, summarized in Table V (overleaf), suggest that reduction of concentration of glycerol and DMSO had improved the qualities of corneal tissue from eyes stored at $-79^{\circ} \mathrm{C}$. This confirmed the impression given by the control experiments using unfrozen corneal tissue.

\section{Histological Appearances}

Histological sections were prepared from the anterior segments of eyes fixed at intervals varying from 2 weeks to 6 months after keratoplasty. The appearances of clear grafts from eyes frozen for varying periods and of the host-graft junctions were 
TABLE V

FROZEN GRAFTS FROM EYES INJECTED WITH 7.5 PER CENT. D.M.S.O. AND SUSPENDED IN 10 PER CENT. GLYCEROL. DILUTION OF GLYCEROL TO 0 PER CENT. AND RE-IRRIGATION WITH 2.5 PER CENT. D.M.S.O. BEFORE OPERATION

\begin{tabular}{c|c|c|c|c|c}
\hline \multirow{2}{*}{ Number of Rabbits } & \multirow{2}{*}{ Days of Storage } & \multicolumn{4}{|c}{ Clear Grafts* } \\
\cline { 2 - 5 } & & At Operation & 3 wks later & 8 wks later & 12 wks later \\
\hline 5 & 8 & 5 & 3 & 3 & 3 \\
\hline 5 & 11 & 3 & 3 & 4 & 4 \\
\hline 2 & 54 & 2 & 1 & 1 & 2 \\
\hline 1 & 67 & 0 & 0 & 0 & 1 \\
\hline 1 & 71 & 1 & 0 & 0 & 0 \\
\hline
\end{tabular}

* Proportion of clear grafts $10 / 14$

compared with the appearances of the same areas in the control grafts of unfrozen tissue. Within 1 month of keratoplasty there was a continuous layer of stratified squamous epithelium over the frozen grafts and their controls. At the host-graft junction there was a slight narrowing of the corneal stroma and the number of nuclei of keratoblasts was locally increased. In some instances, particularly at the shorter intervals after grafting, small numbers of capillaries were present in the stroma in the region of the host-graft junctions and there was a variable infiltration with round cells. Neither the vascularity nor the cellular infiltration was more conspicuous in frozen than in fresh grafts 1 to 6 months after operation. The stroma of the grafts of both fresh and frozen tissue was thicker than the stroma of the host cornea and this thickening persisted for 6 months.

The cut ends of Descemet's membrane were sometimes recurved and sometimes tapered off gradually both in the host and in the graft cornea. In other instances the cut ends appeared to have become frayed out (see Plate III, Figs 17-20). The gap between them was filled by cells with larger, paler nuclei than the normal resting keratoblasts and by structureless fibrils with the same staining reactions as normal stromal fibrils. A delicate membrane which stained in the same way as the original Descemet's membrane could usually be detected within 1 month of keratoplasty. It was in close contact with the endothelial layer, which continued uninterrupted from the inner surface of the host cornea across the host-graft junction to line the graft.

The histological studies are to be continued and will later be reported in detail.

\section{Discussion}

The difficulties of full-thickness keratoplasty using unfrozen material in the rabbit have been described previously (Mueller and Smith, 1963). Some of these difficulties have since been overcome. For instance, mydriasis during and after operation became less important and anterior synechiae did not form if the pupil had been kept dilated beyond the host-graft junction during operation. Early vascularization of the host and graft cornea was usually seen in rabbit eyes in which the donor material had been treated with media containing horse serum. The wound healed well and 


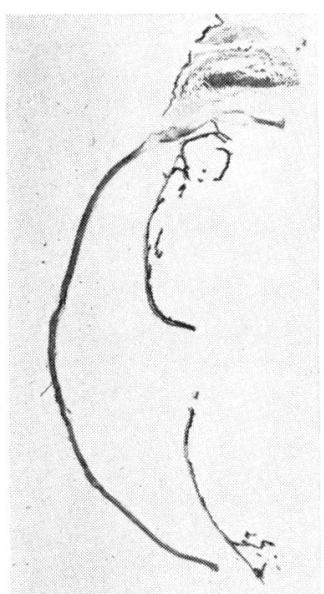

13

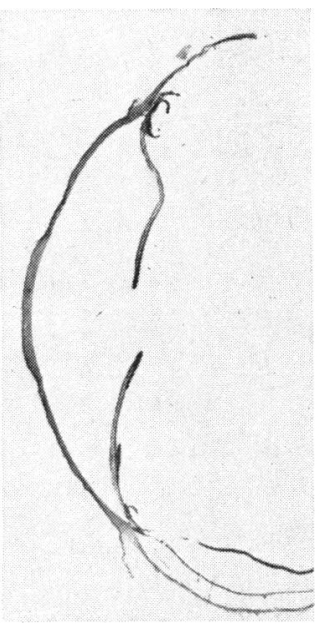

14

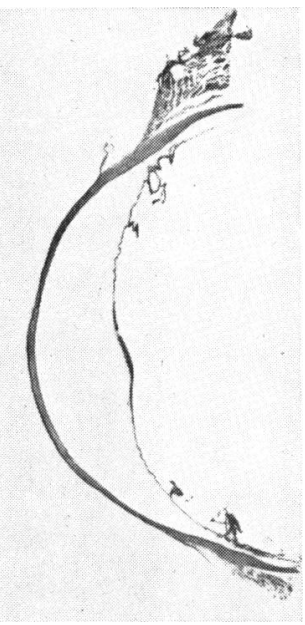

15

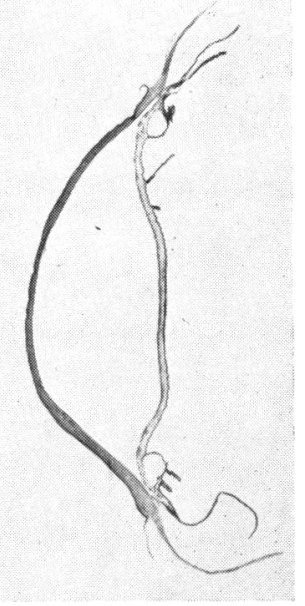

16

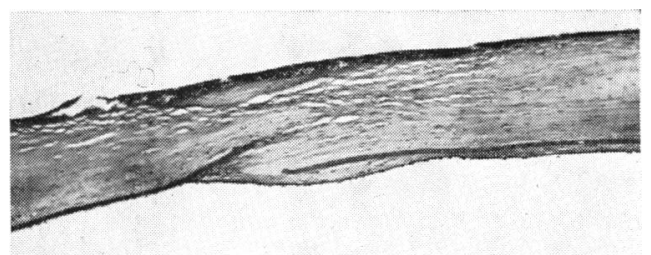

18

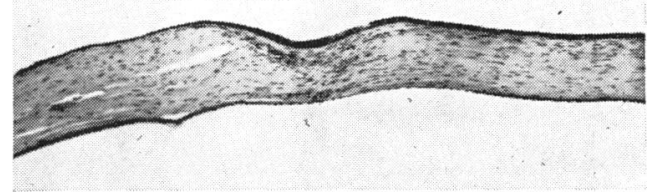

20

Plate III

Histological sections of rabbit eyes with full-thickness homografts from unfrozen control eyes or from frozen eyes, stained with the periodic-acid Schiff reagent.

FIGs 13 to 16 show the entire cornea. $\times 3 \cdot 3$.

Figs 17 to 20 show the host-graft junction. $\times 48$.

FIGS 13 and 17.-Control graft, 26 weeks after operation.

FIGS 14 and 18.-Graft from eye frozen 2 hrs. at $-79^{\circ} \mathrm{C}$., 26 weeks after operation.

FIGs 15 and 19.-Control graft, 12 weeks after operation.

FIGs 16 and 20.-Graft from eye frozen 11 days at $-79^{\circ} \mathrm{C}$., 12 weeks after operation.

the vessels regressed after 2 to 3 weeks and did not appear to have a harmful effect so far as eventual clearing of the graft was concerned. It was remarkable that blood vessels were absent in full-thickness corneal grafts from eyes treated with media containing rabbit serum; subsequent ectasia or formation of anterior synechiae due to partial separation of the graft occurred frequently; extensive rupture at the host-graft junction occasionally occurred as a result of retarded wound healing. There is no evidence that any of the failures was due to immunological factors. The 
beneficial results of using horse serum as a diluting medium in our experiments on rabbit eyes must not be taken as a recommendation for its use in banking the human eye; on the contrary, treatment of donor eyes with horse serum must be avoided because of the risk that the patients to receive grafts might already have become allergic to horse serum.

A continuous suture was used for fixing the graft in the experiments described here. Indirect overlay sutures, of which I have no personal experience, are successfully used by many surgeons for keratoplasty in man and other mammals (Leigh and Ridge, 1957; Stocker and others, 1960). This type of fixation might give as good or even better results when grafting the full-thickness of frozen corneal tissue in rabbits.

On the rare occasions when the lids were sutured over the operated eyes the spread of new epithelium over the graft was slowed and corneal sutures cut out. These complications were probably due to movements of the operated eye under the closed lid. The normal eye must, of course, always be left open in an experimental animal.

It seems quite clear that the corneal epithelium survives freezing better in the presence of glycerol than in the presence of dimethyl sulphoxide (Smith and others, 1963). This was confirmed by Platts and Reed (1963) in studies of frozen corneal tissue from rabbits and other mammals using a technique of tissue culture in which preferential growth of corneal epithelium would have taken place. By contrast, there is evidence that dimethyl sulphoxide is more effective than glycerol in protecting the corneal endothelium during freezing and thawing (Smith and others, 1963). The fact that the cornea is impermeable to both these substances enabled us to use them both to their best advantage for banking intact eyes (Mueller and Smith, 1963). In the future, use of one of the new protective agents (Nash, 1962) or alterations of other constituents of the medium may make it possible to preserve the anterior half of the eye or even discs of corneal tissue in the frozen state at very low temperatures.

The data include results of pioneer experiments. We are therefore assaying progress of skill in preparing eyes for banking and in the technique of keratoplasty in the rabbit as well as the effects of prolonged low-temperature storage. The many failures in the early experiments when grafting fresh and frozen corneal tissue were due, in part at least, to insufficient surgical experience. Some of the later failures occurred with eyes which had been kept at $-79^{\circ} \mathrm{C}$. for the long periods and which had been unskilfully prepared for freezing. When these eyes were thawed their anterior chambers were, in several instances, completely empty because of leakage, while others contained large air bubbles. In others there was a needle track through the lens suggesting that the anterior chamber had not, in fact, been irrigated by the protective medium. Some of the ampoules which had been banked for more than 2 months had been sealed by a faulty technique and had cracked, so that alcohol saturated with carbon dioxide at $-79^{\circ} \mathrm{C}$. had entered. When the ampoules were intact, some eyes kept for as long as 114 days gave clear full-thickness grafts. The results suggest that human eyes suitably prepared could be kept for 2 to 3 months at $-79^{\circ} \mathrm{C}$.

Banking in liquid nitrogen at $-196^{\circ} \mathrm{C}$., as recommended for other cells and tissue by Rinfret (1963), Moline (1963), and Meryman (1956, 1963), might make it possible to preserve the human cornea for years for full-thickness keratoplasty. On the other hand, this would increase the expense of banking and the technical difficulties of rapid thawing in the operating theatre. Storage of donor material for 2 months at 
$-79^{\circ} \mathrm{C}$. before use for full-thickness corneal grafts should, however, reduce the present shortage of donor eyes. A modest start has been made at the Westminster Hospital in banking human eyes by the technique described. The results with this banked material for full-thickness grafts are so far very promising. They will form the subject of a later report.

\section{Summary}

A standard technique has been developed for homografting the full thickness of fresh or frozen rabbit cornea. The grafts were cut with a $6 \cdot 1-\mathrm{mm}$. trephine and fixed with a continuous suture. 98 per cent. of the grafts of fresh unfrozen corneal tissue became and remained clear.

The method finally adopted for preparing donor eyes for freezing was to irrigate the anterior chambers with a solution containing 7.5 per cent. dimethyl sulphoxide and to suspend the intact eyes in a medium containing 10 per cent. glycerol. They were sealed in glass ampoules which were cooled slowly to and stored at $-79^{\circ} \mathrm{C}$. The frozen eyes were thawed rapidly and grafts were cut just before operation.

Using these techniques, seventeen out of twenty of the grafts from eyes frozen for 1 to $2 \mathrm{hrs}$ were clear from the 4th post-operative week onwards. Eighteen out of twenty of the grafts from eyes kept for 1 to 51 days at $-79^{\circ} \mathrm{C}$. were clear 8 weeks after operation and thereafter. Nine out of eighteen of the grafts from eyes kept for 62 to 114 days were clear by the 16 th week after operation. Technical errors rather than prolonged storage were responsible for the failures in this group.

Clear full-thickness grafts were obtained from rabbit eyes which had been banked at $-79^{\circ} \mathrm{C}$. for 106 and 114 days.

I wish to thank Sir Benjamin Rycroft for his encouragement and support. I am particularly grateful to the Medical Research Council for a personal grant, and to Sir Charles Harington and Dr. P. B. Medawar for allowing me to work at the National Institute for Medical Research, Mill Hill. It is a pleasure to acknowledge the help of Dr. Audrey U. Smith in the experiments on freezing and in writing this paper.

My thanks are also due to Sister K. King who cared for my instruments, to Mr. F. Summers, Pharmacist at the Queen Victoria Hospital, East Grinstead, for his advice on drugs, and to the staff of the National Institute for Medical Research, for their technical help; Mr. F. Crisp was the anaesthetist; Miss Barbara Bayley assisted during operations, and prepared the histological sections. Mr. D. Short and the staff of the Animal Division looked after the rabbits. Mr. F. Wanless prepared the illustrations.

\section{REFERENCES}

Eastcott, H. H. G., Cross, A. G., Leigh, A. G., and North, D. P. (1954). Lancet, 1, 237.

KING, J. H., Jr. (1960). Surv. Ophthal., 5, 253.

LEIGH, A. G., and RIDGE, J. W. (1957). Trans. ophthal. Soc. U.K., 77, 367.

MERYMAN, H. T. (1956). Science, 124, 515. (1963). Fed. Proc., 22, 81.

Moline, S. W. (1963). Linde Reports on Advances in Cryobiology.

Mueller, F. O., and Smith, A. U. (1963). Exp. Eye Res., 2, 237.

NASH, T. (1962). J. gen. Physiol., 46, 167.

PlatTs, S., and ReED, H. (1963). Brit. J. Ophthal., 47, 334.

Polge, C., and Lovelock, J. E. (1952). Vet. Rec., 64, 396, 851.

Rinfret, A. P. (1963). Fed. Proc., 22, 94.

RYCROFT, B. W. (1953). Brit.J. Ophthal., 37, 349.

- (1955). "Corneal Grafts". Butterworth, London. (1962). Lancet, 1, 147.

Sмгтн, A. U. (1962). Int. Ophthal. Clin., 2, 731.

, Ashwood-Simith, M. J., and Young, M. R. (1963). Exp. Eye Res., $2,71$.

Stocker, F. W., Matton, M. T., Eiring, A., Georgiade, R., and Georgiade, N. (1960). Amer.J. Ophthal., 49, 729. 